
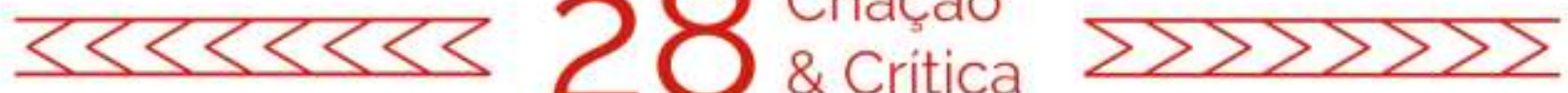

\title{
ERA RECIFE
}

Ana Paula Albé ${ }^{1}$

RESUMO: texto poético e performativo escrito a partir das experiências inventadas e vividas pela artista entre os anos 2008 e 2014. Destaca-se a produção do percurso performativo Walking Poem Recife, realizada durante o Festival de Dança de Recife em 2008, junto a companhia dinamarquesa Hello!Earth.

PALAVRAS-CHAVE: Poesia e performance; Recife; Encontros.

\section{ERA RECIFE}

ABSTRACT: a poetic and performative text written from the invented and lived experiences by the artist between 2008 and 2014. Walking Poem Recife is the main reference, a performative travel developed during the Recife Dance Festival in 2008, with the danish art group Hello! Earth.

KEYWORDS: Poetry and performance; Recife; Meetings.

\section{Era Recife.}

Centro.

Apesar do calor ser dissipado pela permanente brisa da cidade, Continuava quente e úmido. Eu saí caminhando pela cidade velha rumo à Praça do Diário

Cruzando a ponte, você me olha, me sorri

eu sorrio.

Você me faz parar.

Ficamos os dois parados na parte alta da ponte.

O vento misturava o cheiro da água salgada do mar com o doce do rio.

Ambas turvas, ambos mexidos.

Nos viramos para o mar, observamos o encontro das águas

Você continua me sorrindo. Estende a mão e me dá um aquário com água translúcida Eu aguardo

Então suas duas mãos abraçam a minha mão direita

Entre as nossas mãos, vibra um peixe

1 Artista brasileira de artes performáticas e audiovisuais. Doutoranda em Poéticas Visuais na ECA/USP (anapaulaalbe@usp.br). 

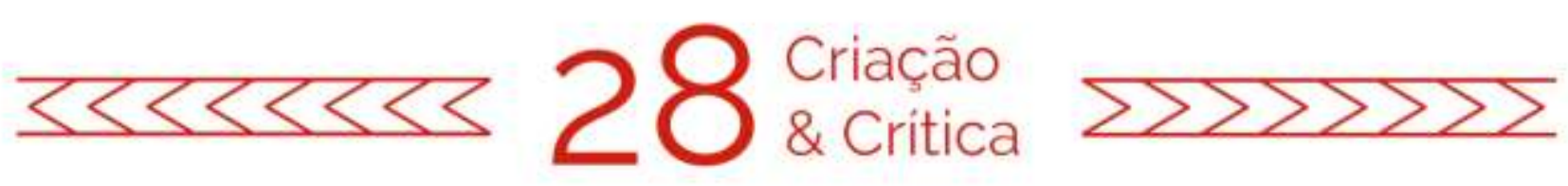

Peixe pequeno e urgente

Minha mão esquerda carrega um mundo limpo, previsível, limitado

Minha mão direita carrega a vida, o tempo

À minha frente está o horizonte, a linha distante entre o mar e o céu

Lá embaixo, o encontro das águas poluídas pela cidade leva tanto a vida quanto a morte

Antes de partir, você diz:

- Está nas suas mãos. Agora é você quem decide.

\section{Contextualização}

A performance Walking Poem Recife realizada em 2008 foi criada durante e para o Festival de Dança de Recife. Por duas semanas, os diretores artísticos da companhia, Vera Maeder e Jacob Langa-Sennek, e os artistas brasileiros Ana Paula Albé e João Cavalcanti juntaram-se aos colaboradores artísticos locais para desenvolver um trajeto a ser percorrido na parte antiga da cidade de Recife. Este trajeto, que a companhia define como "perfomative travels", foi criado pelo mapeamento da área onde se daria o festival. Definimos pontos da cidade interessantes para "shifts of perception" (deslocamentos de percepção) dos espaços urbanos. O público caminhava individualmente pela cidade, que lhe é, além de comum, extremamente familiar. Apesar de estar no mesmo lugar onde passava todos os dias, a vida inteira, as ações criadas pela companhia faziam com que o público percorresse a cidade através de uma nova percepção poética.

Venho trabalhando com o Hello!Earth desde 2007, quando os conheci no Festival Panorama de Dança no Rio de Janeiro. Nessa época, produzi para o projeto o vídeo "Invisible Reality Show", criado por eles para o festival. Em 2008, fui convidada a participar como colaboradora artística e assistente de direção na turnê da companhia pelo Brasil. Foram 3 festivais: o Panorama (RJ), o Festival da Dança de Recife (PE) e a Mostra SESC de Artes (SP). Em 2009, fui indicada por eles para um grande projeto solo em Bangalore (Índia). Em 2010, nos reencontramos em Copenhagen no festival My Images com o projeto "1\&1=1". Em 2013 fizemos o Re-Everything, na residência artística TRANSFORMA, em Torres Vedras (Portugal).

O processo de desenvolvimento deste projeto se deu como os outros que são desenvolvidos na companhia: Vera e Jacob, diretores artísticos da companhia, são os codiretores e, em cada cidade, convocam artistas locais para compor ações que digam respeito àquela cultura específica. Para isso, sugerem jogos corporais; práticas teatrais para 

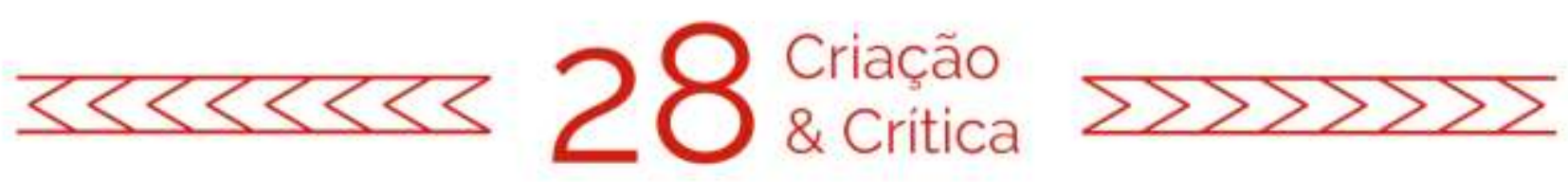

provocar os colaboradores a compor cenas; e situações urbanas que criem uma nova percepção a partir do vocabulário cultural específico daquela cidade.

Em Recife, dentre os colaboradores, havia um poeta, autor do texto inicial do vídeo. Além dele, havia um performer, uma bailarina, um capoeirista, uma professora de pilates, um ator, uma jornalista, e outros participantes de diversos backgrounds, sempre muito bemvindos nesse projeto. Como era a assistente de direção, fazia a mediação entre a companhia e os produtores do festival, bem como com participantes e com a própria cidade. Uma pessoa por vez poderia participar como público, com saídas a cada quinze minutos, seguindo um roteiro extremamente preciso e calculado embora invisível aos que não estavam participando dessa organização. O participante recebia uma orientação: ao sair da bilheteria do teatro, deveria ligar o som do pequeno aparelho que recebia, pôr o fone no ouvido e seguir por uma rua, virando depois à esquerda e seguindo por outra rua até encontrar a pessoa de blusa vermelha. Caminhava ouvindo o áudio e, ao notar uma pessoa vestida com blusa vermelha, olhando fixamente para ele, se detinha. Essa pessoa da blusa vermelha se aproximava, retirava cautelosamente o fone e o aparelho da mão do participante e pedia que fechasse os olhos. Ao fechar os olhos, era guiado por este rapaz de blusa vermelha, por um percurso sonoro. O rapaz avisava então: "vou te deixar aqui: abra lentamente os olhos e siga pela ponte". O participante abria os olhos, em uma rua muito movimentada, atravessava esse percurso e subia a "Ponte Velha". Na parte alta da ponte, um rapaz alto e magro aguardava 0 participante, com um sorriso largo no rosto. $O$ contato se dava: o reconhecimento entre 0 participante e o artista se dava através dos olhares, e aos poucos o participante se distanciava da confusão da cidade e se permitia se envolver por esses colaboradores.

O trabalho desenvolvido por mim começava neste ponto, nesta ação composta por mim: o rapaz alto e magro sorria para o participante e se virava para o mar, para o encontro entre o mar e o rio, que acontece embaixo da ponte. Em seguida ele pedia a mão do participante e lhe dava um saco com água translúcida. Pedia a outra mão e punha ali um peixe vivo, molhado. O participante tinha uma vida nas suas mãos e deveria decidir o que fazer com o peixe: se o entregava ao rio e ao mar, poluídos, ou se leva o peixe consigo, no saquinho de água pura.

As relações entre as imagens do vídeo e o texto se deram através da edição, da montagem do vídeo, já depois do projeto terminado. Existiu um desejo da minha parte, como editora do vídeo, de não cobrir os textos com imagens descritivas, buscando provocar uma experiência por meio desse vídeo, que embora seja um registro do projeto, também se propõe como uma obra poética. Os cortes e as transições entre as imagens são sobretudo secos e as passagens são realizadas através da banda de áudio.

A ação que compus para esse percurso era muito forte e gerava um desconforto em todos, pois exigia uma decisão, uma posição para o público, que costuma assumir uma posição passiva ao assistir e participar de trabalhos de arte. Eu tentava criar um registro 

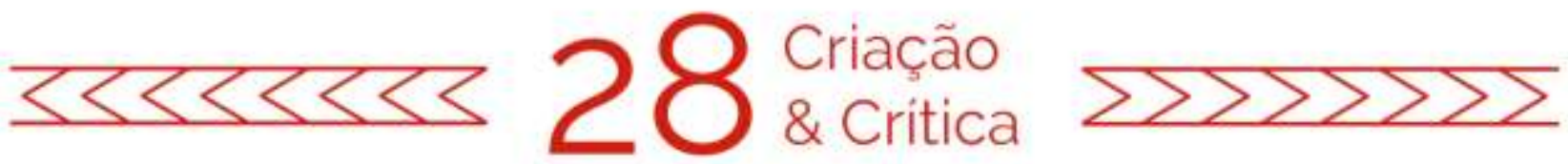

daquela ação, que era documentação de um ato efêmero. Comecei a escrever sobre a proposta realizada e notei que tal ação se deslocava facilmente daquele projeto maior e funcionava como escrita. O texto apresentado acima, salvando as adaptações necessárias deste suporte gráfico, mantém a latência e a urgência do tempo presente.

\section{Referência}

Hello!Earth. Walking Poem Recife, a performative travel. 13ํ Festival Internacional de Dança de Recife, 2008. Vídeo disponível em: < https://www.youtube.com/watch?v=_k-C-9_NqkU>. Ficha técnica disponível em: < https://www.helloearth.cc/archiverecife>. Acesso em: 07 nov. 2020.

Recebido em: 24/08/2020 Aceito em: 24/08/2020

Referência eletrônica: ALBÉ, Ana Paula. Era Recife. Criação \& Crítica, n. 28, p., dez. 2020. Disponível em: <http://revistas.usp.br/criacaoecritica>. Acesso em: dd mmm. aaaa. 